\title{
Assessment of Body Fat Distribution and Serum Liver- Type Fatty Acid-Binding Protein (L-FABP) and Neutrophil Gelatinase-Associated Lipocalin (NGAL): Potential Noninvasive Markers for Non-Alcoholic Fatty Liver Disease
}

\author{
Moushira Zaki 1, ${ }^{*}$ (i) , Hala El-Bassyouni ${ }^{2(\mathbb{D})}$, Mona Abd Elmotaleb A Hussein ${ }^{3(\mathbb{D})}$, Mina Wassef Girgiss ${ }^{4}$, \\ Eman R. Youness 5 (i)

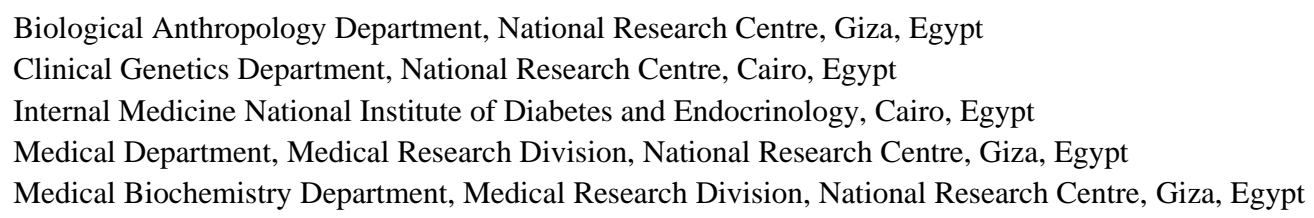

Scopus Author ID 8608622500

Received: 21.01.2021; Revised: 18.02.2021; Accepted: 24.02.2021; Published: 2.03.2021

\begin{abstract}
Previous studies reported significant positive correlations between liver-type fatty acidbinding protein (L-FABP) and neutrophil gelatinase-associated lipocalin (NGAL) marks with obesity. L-FABP is a cytosolic protein that modulates fatty acid metabolism, and NGALs a biomarker of inflammation and infection. Our objective was to investigate levels of NGAL and L-FABP in the serum of women with non-alcoholic fatty liver disease (NAFLD) and determine their diagnostic values. The subjects of this study comprised 150 women: 75 with NAFLD and 75 healthy control. Serum L-FABP and NGAL levels were determined by a sandwich enzyme-linked immunosorbent assay. Serum lipids were measured by enzymatic colorimetric methods. The abdominal fat was assessed by waist circumference (WC) and defined as $\mathrm{WC} \geq 88 \mathrm{~cm} 2$. Visceral fat thicknesses (VFT) were investigated ultrasonographically. Anthropometry and systolic and diastolic blood pressure (BP) were taken. Body composition was measured by Tanita Body Composition Analyzer (SC-330). NAFLD patients were diagnosed with elevated transaminases and with steatosis by ultrasonography. Serum NGAL, L-FABP, WC, triglycerides, LDL-C, VFT, systolic and diastolic BP were significantly higher in NAFLD than controls. Significant positive correlations were observed between serum NGAL and L-FABP and adiposity parameters (WC and VFT), body fat\% and blood pressure, AST and ALT levels. NGAL and L-FABP might be used as novel biomarkers for early detection of NAFLD and metabolic abnormalities. Elevated NGAL and L-FABP were associated with adiposity parameters, serum lipids, blood pressure, AST and ALT levels, which suggest the relationship of body fat distribution and lipid metabolism in NAFLD. Investigation of the two biomarkers and body fat content could serve as novel noninvasive diagnostic markers for NAFLD, propose a new perception for NAFLD's therapeutic interference, and might be useful biomarkers for detecting the preclinical stage of the metabolic abnormalities in the general population.
\end{abstract}

Keywords: neutrophil gelatinase-associated lipocalin; liver-type fatty acid-binding protein; visceral fat thicknesses; waist circumference; lipid profile; NAFLD.

(C) 2021 by the authors. This article is an open-access article distributed under the terms and conditions of the Creative Commons Attribution (CC BY) license (https://creativecommons.org/licenses/by/4.0/). 


\section{Introduction}

The most common risk factor for metabolic syndrome is obesity that is characterized by an excess of adipose tissue and a bunch of abnormalities comprising dyslipidemia, atherosclerosis, type 2 diabetes, insulin resistance, and hypertension [1]. The proper cut-off point of waist circumference in screening for NAFLD was $84 \mathrm{~cm}$ for women and the optimal cut-off point of waist-height ratio 0.57 for women, and the cut-off point of the waist to hip ratio was 0.94 for men and 0.87 for women with very good specificity and sensitivity [2].

Diagnosing and treating hyperlipidemia is an important way to avoid cardiovascular disease (CVD) [3]. L-FABP belongs to the fatty-acid-binding proteins superfamily and is generally expressed in the liver [4]. Furthermore, L-FABP is a crucial regulator of hepatic lipid metabolism as it interacts with the peroxisome proliferator-associated receptors (PPARs). Thus L-FABP plays an indispensable role in many enzyme activations that are implicated in fatty acid metabolism [5].

Neutrophil gelatinase-associated lipocalin (NGAL), which is mostly liberated from the activated neutrophils' granules, is renowned as an acute phase protein [6]. L-FABP is a plentiful protein in hepatocytes that binds most of the long-chain fatty acids existing in the cytosol [7]. In the hepatic lobule, L-FABP is expressed in hepatocytes in a diminishing gradient from portal to central location [7].

Increased levels of NGAL have been described in atherosclerosis and related to inflammatory progressions [8]. Previous studies have shown that NGAL is also expressed in cardiomyocytes and macrophages in atherosclerotic plaque [9-11]. The liver biopsy is an inadequate screening tool for the NAFLD diagnosis in the general inhabitants [12].

The purpose of the current work was to investigate L-FABP and NGAL levels in patients with non-alcoholic fatty liver disease and determine their diagnostic values (NAFLD) and explore the role of body fat content.

\section{Materials and Methods}

The study recruited 75 women with the non-alcoholic fatty liver disease diagnosed with elevated transaminases and steatosis as detected by ultrasonography. The control group included age and gender-matched healthy subjects. Patients with a history of viral hepatitis, coronary artery disease, intervention coronary angiography or any heart disease (congestive heart failure, cardiomyopathy), hypertension, diabetes mellitus, renal failure, or patients with any systemic disease were excluded.

The anthropometric measurements and ultrasonography measurements of visceral abdominal fat layers were performed as described previously [13, 14].

The cut-off point of waist circumference in screening for NAFLD was $>84 \mathrm{~cm}$ for women [15].

The plasma L-FABP and NGAL were measured in duplicate using enzyme-linked immunosorbent assay (ELISA) kits.

The study was approved by the National Research Centre ethics committee, and each participant gave written informed consent.

\subsection{Statistical analyses.}

All statistical analyses were performed using SPSS for Windows software (version 20.0; SPSS Inc., Chicago, IL, USA). 


\section{Results and Discussion}

The clinical characteristics of the subjects are shown in Table 1. Patients with NAFLD had significantly elevated levels of NGAL, L-FABP, VFT, WC, LDL-C, TG and blood pressure compared to controls. Also, NGAL and L-FABP significantly correlated with body fat parameters and blood pressure levels (Table 2).

Figures 1 and 2 showed Box-and-whisker plots of serum levels of NGAL and L-FABP in controls and patients.

Figures 3 and 4 showed Box-and-whisker plots of serum levels of NGAL and L-FABP by WC for controls and patients.

NAFLD affects $16 \%-23 \%$ of the general population; it is a disorder strongly related to obesity, with a described incidence as high as $80 \%$ in obese patients [16]. L-FABP is a promising biochemical marker for detecting hepatocellular injury next liver transplantation [4, 7]. Intracellular lipid chaperones recognized as fatty acid-binding proteins (FABPs) organize the lipid responses in the cells. The abdominal fats are considered the significant determining factor of metabolic risk, as the pro-inflammatory adipokines released via visceral fats are interrelated with insulin resistance, dyslipidemia, and increased blood pressure [2]. In our report, L-FABP levels were elevated in NAFLD patients in comparison with the control group. This corroborates with the findings of [17].

NGAL is an imperative regulator of the peroxisome proliferator-activated receptors $\gamma$ (PPAR $\gamma$ ) activity that is implicated in the regulation of lipogenesis and adipogenesis in the liver and adipose tissue. Consequently, NGAL plays a vital role in glycolipids regulation [18-20]. In our study, WC, triglycerides, LDL-C, and VFT were significantly higher in NAFLD patients than in controls.

The WC has proven to be linked to the severity of non-alcoholic fatty liver disease $[21,22]$. Furthermore, other studies [23, 24] noted that the triglycerides and LDL-C were significantly increased in the patients with NAFLD. Our results agree with several studies that stated that VFT positively correlated with NGAL and can be a supplementary parameter in NAFLD grading [17, 25].

Previous studies delineated that the concentration of NGAL was directly interrelated with obesity, hypercholesterolemia, and hyperglycemia in patients with cardiovascular and metabolic diseases, which are chief risk factors for non-alcoholic fatty liver disease (NAFLD) [26-30].

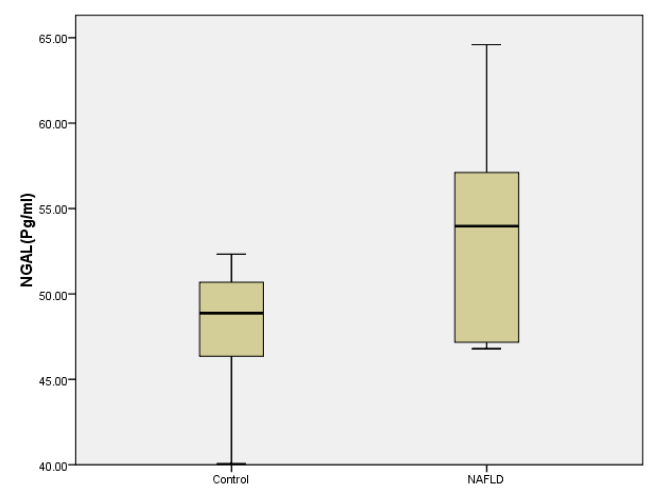

Figure 1. Box-and-whisker plots display serum NGAL levels in control and NAFLD. The central line in each box indicates the sample median. The boxes represent the 25 th and $75^{\text {th }}$ percentile, whiskers represent the minimum and maximum of observed values. 


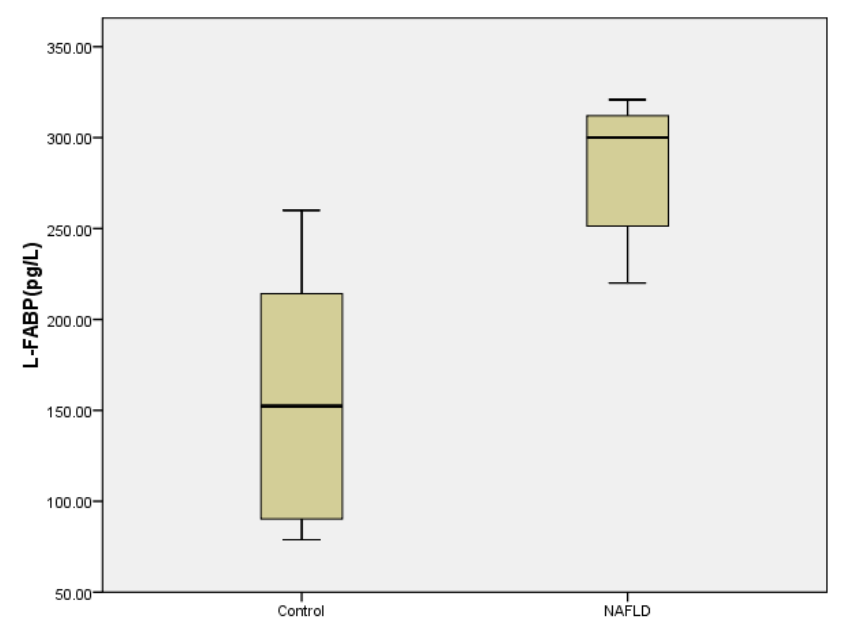

Figure 2. Box-and-whisker plots display serum levels of L-FABP in control and NAFLD. The central line in each box indicates the sample median. The boxes represent the 25 th and $75^{\text {th }}$ percentile, whiskers represent the minimum and maximum of observed values.

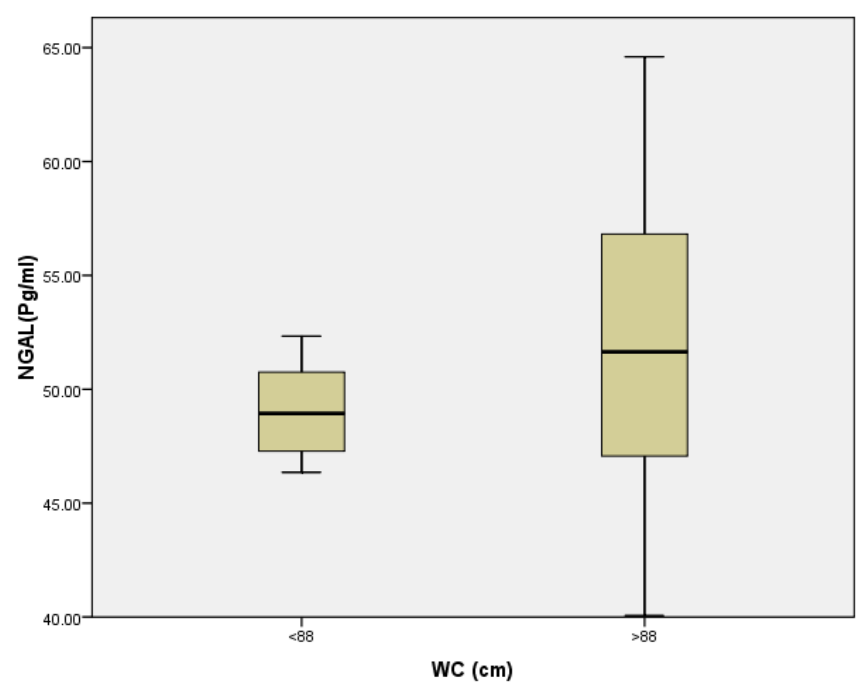

Figure 3. Box-and-whisker plots display serum levels of NAGL by WC cut-off points. The central line in each box indicates the sample median. The boxes represent the 25 th and $75^{\text {th }}$ percentile, whiskers represent the minimum and maximum of observed values.

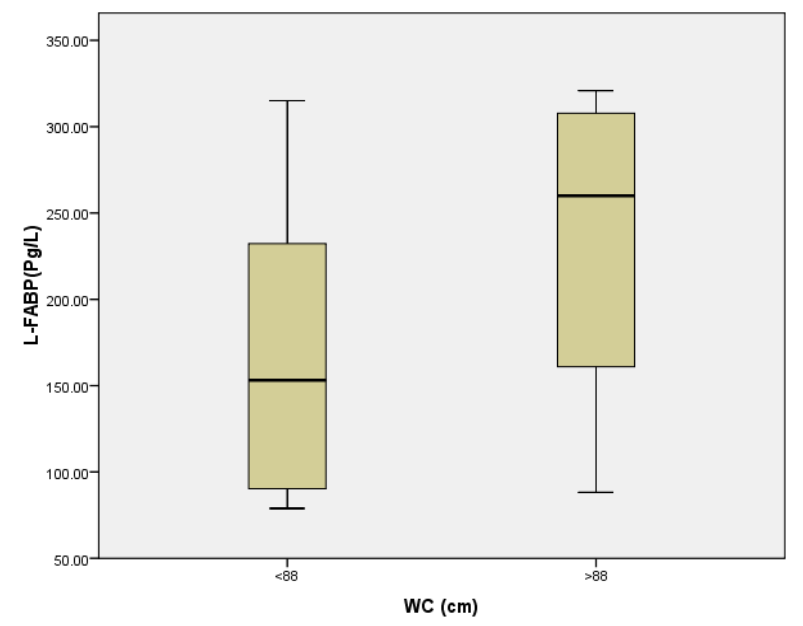

Figure 4. Box-and-whisker plots display serum levels of L-FABP by WC cut-off points. 
Table 1. Clinical Characteristics of the study subjects.

\begin{tabular}{l|c|c} 
Variables & Group & Mean \pm SD \\
\hline \multirow{2}{*}{ BMI $(\mathrm{kg} / \mathrm{m} 2)$} & Control & $24.21 \pm 4.14$ \\
\cline { 2 - 3 } & NAFLD & $34.97 \pm 3.717^{*}$ \\
\hline \multirow{2}{*}{ NGAL $(\mathrm{pg} / \mathrm{ml})$} & Control & $47.62 \pm 3.80$ \\
\cline { 2 - 3 } & NAFLD & $53.80 \pm 5.65^{*}$ \\
\hline \multirow{2}{*}{ L-FABP $(\mathrm{pg} / \mathrm{ml})$} & Control & $155.94 \pm 63.23$ \\
\cline { 2 - 3 } & NAFLD & $274.10 \pm 52.61^{*}$ \\
\hline \multirow{2}{*}{ Triglycerides } & Control & $106.39 \pm 36.745$ \\
\cline { 2 - 3 } & NAFLD & $151.34 \pm 33.12^{*}$ \\
\hline \multirow{2}{*}{ WC $(\mathrm{cm})$} & Control & $97.57 \pm 22.50$ \\
\cline { 2 - 3 } & NAFLD & $174.80 \pm 16.612^{*}$ \\
\hline \multirow{2}{*}{ Systolic PB $(\mathrm{mm} \mathrm{Hg})$} & Control & $80.78 \pm 19.523$ \\
\cline { 2 - 3 } & NAFLD & $95.48 \pm 9.55^{*}$ \\
\hline \multirow{2}{*}{ Systolic PB $(\mathrm{mm} \mathrm{Hg})$} & Control & $104.70 \pm 11.357$ \\
\cline { 2 - 3 } & NAFLD & $113.62 \pm 14.510^{*}$ \\
\cline { 2 - 3 } & Control & $69.20 \pm 7.44$ \\
\hline \multirow{2}{*}{ VFT $(\mathrm{mm})$} & NAFLD & $73.97 \pm 8.38^{*}$ \\
\cline { 2 - 3 } & Control & $3.48 \pm 1.01$ \\
\hline
\end{tabular}

BMI: body mass index; WC: waist circumference; VFT: visceral fat thicknesses

$* P<0.05, * * P<0.01$

Table 2. Correlations of L-FABP and NGAL serum levels with body fat parameters, AST and ALT and serum lipids in NAFLD.

\begin{tabular}{l|l|l} 
Variables & L-FABP & NGAL \\
\hline Visceral fat $(\mathrm{mm})$ & $0.57^{* *}$ & $0.55^{* *}$ \\
\hline WC $(\mathrm{cm})$ & $0.56^{* *}$ & $0.53^{* *}$ \\
\hline Fat $\%$ & $0.38^{*}$ & $0.31^{*}$ \\
\hline Waist-to-hip ratio & $0.34^{* *}$ & 0.21 \\
\hline BMI $(\mathrm{kg} / \mathrm{m} 2)$ & $0.53^{* *}$ & $0.41^{* *}$ \\
\hline Fat mass & $0.39^{* *}$ & $0.54^{*}$ \\
\hline Mid upper arm circumference $(\mathrm{cm})$ & $0.42^{* *}$ & 0.15 \\
\hline LDL-C & $0.52^{* *}$ & $0.45^{* *}$ \\
\hline Triglycerides & $0.55^{* *}$ & $0.45^{* *}$ \\
\hline ALT $(\mathrm{U} / \mathrm{L})$ & $0.54^{* *}$ & $0.44^{* *}$ \\
\hline AST $(\mathrm{U} / \mathrm{L})$ & $0.51^{* *}$ & $0.55^{* *}$ \\
\hline Systolic PB $(\mathrm{mm} \mathrm{Hg})$ & $0.25^{*}$ & $0.30^{*}$ \\
\hline Diastolic PB $(\mathrm{mm} \mathrm{Hg})$ & $0.39^{*}$ & $0.28^{*}$ \\
$* P<0.05, * * P<0.01$ & &
\end{tabular}

\section{Conclusions}

In conclusion, serum NGAL and L-FABP levels positively correlated with body fat parameters and visceral adiposity in NAFLD, suggesting that hormones secreted by body fats probably participate in energy metabolism regulation through different pathways; this may propose a new perception for therapeutic interference of NAFLD.

\section{Funding}

National Research Center, Egypt, project number 16361.

\section{Acknowledgments}

The authors acknowledge the financial assistance provided by the National Research Center, Egypt.

\section{Conflicts of Interest}

The authors declare no conflict of interest. 


\section{References}

1. Xu, A.; Wang, Y.; Xu, J.Y.; Stejskal, D.; Tam, S.; Zhang, J.; Wat, N.M.S.; Wong, W.K.; Lam, K.S.L. Adipocyte fatty acid-binding protein is a plasma biomarker closely associated with obesity and metabolic syndrome. Clin. Chem. 2006, 52, 405-413, https://doi.org/10.1373/clinchem.2005.062463.

2. $\quad$ Singh, A.; Parida, S.; Narayan, J.; Nath, P.; Padhi, P.K.; Pati, G.K.; Parida, P.K.; Meher, C.; Agrawal, O.; Singh, S.P. Simple anthropometric indices are useful for predicting Non-alcoholic Fatty Liver Disease [NAFLD] in Asian Indians. J. Clin. Exp. Hepatol. 2017, 7, 310-315, https://doi.org/10.1016/j.jceh.2017.05.005.

3. Cherry, D.K.; Burt, C.W.; Woodwell, D.A. National ambulatory medical care survey: 1999 summary. 2001.

4. Pelsers, M.M.A.L.; Namiot, Z.; Kisielewski, W.; Namiot, A.; Januszkiewicz, M.; Hermens, W.T.; Glatz, J.F.C. Intestinal-type and liver-type fatty acid-binding protein in the intestine. Tissue distribution and clinical utility. Clin. Biochem. 2003, 36, 529-535, https://doi.org/10.1016/S0009-9120(03)00096-1.

5. Wolfrum, C.; Borrmann, C.M.; Börchers, T.; Spener, F. Fatty acids and hypolipidemic drugs regulate peroxisome proliferator-activated receptors $\alpha$-and $\gamma$-mediated gene expression via liver fatty acid binding protein: a signaling path to the nucleus. Proc. Natl. Acad. Sci. 2001, 98, 2323-2328, https://doi.org/10.1073/pnas.051619898.

6. Liu, Q.; Nilsen-Hamilton, M. Identification of a new acute phase protein. J. Biol. Chem. 1995, 270, 2256522570, https://doi.org/10.1074/jbc.270.38.22565.

7. Akbal, E.; Koçak, E.; Akyürek, Ö.; Köklü, S.; Batgi, H.; Şenes, M. Liver fatty acid-binding protein as a diagnostic marker for non-alcoholic fatty liver disease. Wien. Klin. Wochenschr. 2016, 128, 48-52, https://doi.org/10.1007/s00508-014-0680-8.

8. Sivalingam, Z.; Larsen, S.B.; Grove, E.L.; Hvas, A.-M.; Kristensen, S.D.; Magnusson, N.E. Neutrophil gelatinase-associated lipocalin as a risk marker in cardiovascular disease. Clin. Chem. Lab. Med. 2017, 56, 5-18, https://doi.org/10.1515/cclm-2017-0120.

9. Bu, D.; Hemdahl, A.-L.; Gabrielsen, A.; Fuxe, J.; Zhu, C.; Eriksson, P.; Yan, Z. Induction of neutrophil gelatinase-associated lipocalin in vascular injury via activation of nuclear factor- $\kappa \mathrm{B}$. Am. J. Pathol. 2006, 169, 2245-2253, https://doi.org/10.2353/ajpath.2006.050706.

10. Li, D.; Yan Sun, W.; Fu, B.; Xu, A.; Wang, Y. Lipocalin-2-The myth of its expression and function. Basic Clin. Pharmacol. Toxicol. 2020, 127, 142-151, https://doi.org/10.1111/bcpt.13332.

11. Wu, L.; Gao, X.; Guo, Q.; Li, J.; Yao, J.; Yan, K.; Xu, Y.; Jiang, X.; Ye, D.; Guo, J. The role of neutrophils in innate immunity-driven non-alcoholic steatohepatitis: Lessons learned and future promise. Hepatol. Int. 2020, 14, 652-666, https://doi.org/10.1007/s12072-020-10081-7.

12. Nier, A.; Huber, Y.; Labenz, C.; Michel, M.; Bergheim, I.; Schattenberg, J.M. Adipokines and endotoxemia correlate with hepatic steatosis in non-alcoholic fatty liver disease (NAFLD). Nutrients 2020, 12, https://dx.doi.org/10.3390\%2Fnu12030699.

13. Zaki, M.E.; El-Bassyouni, H.T.; El-Gammal, M.; Kamal, S. Indicators of the metabolic syndrome in obese adolescents. Arch. Med. Sci. 2015, 11, https://doi.org/10.5114/aoms.2015.49214.

14. Zaki, M.E.; Basha, W.; Yousef, R.N.; Awad, M. Serum Vascular Endothelial Growth Factor in Egyptian Obese Women with Insulin Resistance. Open access Maced. J. Med. Sci. 2019, 7.

15. Almeida, N.S.; Rocha, R.; Cotrim, H.P.; Daltro, C. Anthropometric indicators of visceral adiposity as predictors of non-alcoholic fatty liver disease: A review. World J. Hepatol. 2018, 10, 695-701, https://doi.org/10.4254/wjh.v10.i10.695.

16. Moghaddasifar, I.; Lankarani, K.B.; Moosazadeh, M.; Afshari, M.; Ghaemi, A.; Aliramezany, M.; Gharebagh, R.A.; Malary, M. Prevalence of non-alcoholic fatty liver disease and its related factors in Iran. Int. J. organ Transplant. Med. 2016, 7.

17. Luo, Y.; Ma, X.; Pan, X.; Xu, Y.; Xiong, Q.; Xiao, Y.; Bao, Y.; Jia, W. Serum lipocalin-2 levels are positively associated with not only total body fat but also visceral fat area in Chinese men. Medicine (Baltimore) 2016, 95, https://doi.org/10.1097/md.0000000000004039.

18. Komosinska-Vassev, K.; Olczyk, P.; Kuźnik-Trocha, K.; Jura-Półtorak, A.; Derkacz, A.; Purchałka, M.; Telega, A.; Olczyk, K. Circulating C1q/TNF-related protein 3, omentin-1 and NGAL in obese patients with type 2 diabetes during insulin therapy. J. Clin. Med. 2019, 8, https://dx.doi.org/10.3390\%2Fjcm8060805.

19. Dimas, G.G. New insights in NAFLD and diabetic nephropathy in patients with diabetes mellitus type 2. Hell. Diabetol. CHRONICLES 2019, 32, 150-155.

20. Barsoum, I.; Elgohary, M.N.; Bassiony, M.A.A. Lipocalin-2: A novel diagnostic marker for hepatocellular carcinoma. Cancer biomarkers: section $A$ of Disease markers 2020, 28, 523-528, https://doi.org/10.3233/cbm-190084.

21. Jarvis, H.; Craig, D.; Barker, R.; Spiers, G.; Stow, D.; Anstee, Q.M.; Hanratty, B. Metabolic risk factors and incident advanced liver disease in non-alcoholic fatty liver disease (NAFLD): A systematic review and metaanalysis of population-based observational studies. PLoS Med. 2020, 17, https://doi.org/10.1371/journal.pmed.1003100. 
22. Tahir, F.; Majid, Z.; Majid, B.; Ahmed, J.; Zaman, A.; Tariq, M.; Imtiaz, F.; Tahir, S.A. Anthropometric Measurements and Lifestyle Characteristics of Individuals with Non-alcoholic Fatty Liver Disease. Cureus 2020, 12, https://dx.doi.org/10.7759\%2Fcureus.7016.

23. Fujii, Y.; Nouso, K.; Matsushita, H.; Kariyama, K.; Sakurai, T.; Takahashi, Y.; Chiba, H.; Hui, S.-P.; Ito, Y.; Ohta, M. Low-density lipoprotein (LDL)-triglyceride and its ratio to LDL-cholesterol as diagnostic biomarkers for non-alcoholic steatohepatitis. J. Appl. Lab. Med. 2020, 5, 1206-1215, https://doi.org/10.1093/jalm/jfaa044.

24. Shao, J.; Yao, D.; Yao, M.; Peng, T.; Shi, J.; Ji, X. Study on correlation between hepatic fibrosis and fat indexes in patients with NAFLD and Type 2 diabetes mellitus. 2020; https://doi.org/10.21203/rs.3.rs17017/v1.

25. Gubina, N.V.; Kupnovytska, I.H.; Mishchuk, V.H.; Markiv, H.D. Ghrelin Levels and Decreased Kidney Function in Patients with Early Stages of Chronic Kidney Disease Against the Background of Obesity. $J$. Med. Life 2020, 13.

26. Wang, Y.; Lam, K.S.L.; Kraegen, E.W.; Sweeney, G.; Zhang, J.; Tso, A.W.K.; Chow, W.-S.; Wat, N.M.S.; $\mathrm{Xu}$, J.Y.; Hoo, R.L.C. Lipocalin-2 is an inflammatory marker closely associated with obesity, insulin resistance, and hyperglycemia in humans. Clin. Chem. 2007, 53, 34-41, https://doi.org/10.1373/clinchem.2006.075614.

27. Wu, G.; Li, H.; Fang, Q.; Jiang, S.; Zhang, L.; Zhang, J.; Hou, X.; Lu, J.; Bao, Y.; Xu, A. Elevated circulating lipocalin-2 levels independently predict incident cardiovascular events in men in a population-based cohort. Arterioscler. Thromb. Vasc. Biol. 2014, 34, 2457-2464, https://doi.org/10.1161/atvbaha.114.303718.

28. Eilenberg, W.; Stojkovic, S.; Piechota-Polanczyk, A.; Kaider, A.; Kozakowski, N.; Weninger, W.J.; Nanobachvili, J.; Wojta, J.; Huk, I.; Demyanets, S. Neutrophil gelatinase associated lipocalin (NGAL) is elevated in type 2 diabetics with carotid artery stenosis and reduced under metformin treatment. Cardiovasc. Diabetol. 2017, 16, 1-11, https://doi.org/10.1186/s12933-017-0579-6.

29. Kim, J.A.; Choi, K.M. Newly Discovered Adipokines: Pathophysiological Link Between Obesity and Cardiometabolic Disorders. Front. Physiol. 2020, 11, https://dx.doi.org/10.3389\%2Ffphys.2020.568800.

30. Gul, A.; Yilmaz, R.; Ozmen, Z.C.; Gumuser, R.; Demir, O.; Unsal, V. Assessment of renal function in obese and overweight children with NGAL and KIM-1 biomarkers. Nutr. Hosp. Organo Of. la Soc. española Nutr. Parenter. y Enter. 2020, 37, 436-442. 